\section{Remote sensing support for post fire forest management}

\begin{abstract}
Corona $P^{(1)}$, Lamonaca $A^{(1)}$, Chirici $G^{*}(2)$
Abstract: Monitoring of forest burnt areas has several aims: to locate and estimate the extent of such areas; to assess the damages suffered by the forest stands; to check the ability of the ecosystem to naturally recover after the fire; to support the planning of reclamation interventions; to assess the dynamics (pattern and speed) of the natural recovery; to check the outcome of any eventual restoration intervention. Remote sensing is an important source of information to support all such tasks. In the last decades, the effectiveness of remotely sensed imagery is increasing due to the advancement of tools and techniques, and to the lowering of the costs, in relative terms. For an effective support to post-fire management (burnt scar perimeter mapping, damage severity assessment, post-fire vegetation monitoring), a mapping scale of at least 1:10000-1:20000 is required: hence, the selection of remotely sensed data is restricted to aerial imagery and to satellite imagery characterized by high (HR) and, above all, very high (VHR) spatial resolution. In the last decade, $H R$ and VHR passive (optical) remote sensing has widespread, providing affordable multitemporal and multispectral pictures of the considered phenomena, at different scales (spatial, temporal and spectral resolutions) with reference to the monitoring needs. In the light of such a potential, the integration of GPS field survey and imagery by light aerial vectors or VHR satellite is currently sought as a viable option for the post-fire monitoring.
\end{abstract}

Keywords: burnt scar perimeter mapping, post-fire vegetation monitoring, damage severity assessment, high and very high spatial resolution satellite sensors

\section{Introduction}

Designing post-fire management (reclamation and restoration interventions, etc.) in forest burnt stands requires the functional and structural assessment of the landscape mosaic and of the size and behaviour of the considered wildfires. In this framework, monitoring may have several aims to support post-fire management: to locate and estimate the extent of the burnt areas (burnt scar perimeter mapping: e.g., Eva \& Lambin 1998, Smith et al. 2002, Holden et al. 2005); to assess the damages suffered by the forest stands (e.g., McHugh \& Kolb 2003); to check the ability of the ecosystem to naturally recover after the fire (e.g., Henry \& Hope 1998, Diaz-Delgado et al. 2003, Moya

(1) Dipartimento di Scienze dell'Ambiente Forestale e delle sue Risorse, Università della Tuscia, Via San Camillo de Lellis snc, 01100 Viterbo, Italy; ${ }^{(2)}$ Dipartimento di Scienze e Tecnologie per l'Ambiente e il Territorio, Università del Molise, Contrada Fonte Lappone snc, 86090 Pesche (Isernia), Italy

*Corresponding Author: Gherardo Chirici (gherardo.chirici@unimol.it).

Citation: Corona P, Lamonaca A, Chirici G 2008. Remote sensing support for post fire forest management. iForest 1: 6-12 [online: Feb 28, 2008] URL:

http://www.sisef.it/iforest/ et al. 2007); to support the planning of reclamation interventions; to assess the dynamics (pattern and speed) of the natural recovery (e.g., Turner et al. 1997, Davis et al. 2005); to check the outcome of any eventual restoration intervention (e.g., Raftoyannis \& Spanos, 2005).

Remote sensing is a relevant source of information to support all such tasks. However, it must be taken into account that in most Mediterranean countries the average size of forest fires (1980-2005) is currently less than 10 ha. In European central and northern countries the average burnt area is even much smaller, generally less than 1 ha (EC 2006).

During the last summer (year 2007) in the Mediterranean area, especially in Greece and in Italy, a lot of wildfires occurred with a significant impact because of the wide range of economic, political, social and ecological values at stake. At the end of August 2007, Greece asked to activate the International Charter "Space and Major Disasters", where national space agencies and private satellite companies make available remotely sensed data to quickly manage human or natural disasters. In the light of this, satellite images with low (e.g., Noaa Avhrr, Modis, Spot-Vegetation) or medium (e.g., WiFS-IRS) spatial resolutions may be exploited for monitoring the largest wildfires, as, for instance, it is carried out by the European Forest Fire Information System (EFFIS, see EC 2006) whit reference to those ones larger than 50 ha using Modis satellite images.

As concerns post-fire forest management, a mapping scale of at least 1:10000-1:20000 is required for an effective support to operational measures like legal constraints enforcing and reclamation and restoration interventions: hence, the selection of remotely sensed data is restricted to aerial imagery and satellite imagery characterized by high (e.g., Spot HVR, IRS LissIII, Aster) and, above all, very high (aerial imagery, Ikonos, QuickBird, Spot 5 and the upcoming WorldView-1 and GeoEye-1) spatial resolution.

For instance, in Italy the national regulation about forest fires (National Law no. $353 / 2000$ ) requires the implementation of a cadastral geodatabase of the burnt areas. For such a purpose, the boundary of all the burnt forest stands have to be overlaid with digital cadastral maps in order to identify land ownership and to prevent possible illegal postfire activities such as land use changes (typically, for grazing or settlements). In this context, the Italian National Forest Service has decided to map burnt forest stands at a scale of at least 1:5000 (minimum mapping unit equal to $625 \mathrm{~m}^{2}$ ), in addition to the historical archives censued since 1970.

The aim of this note, which update and widen a previous overview (Chirici \& Corona 2005), is to selectively present, as a commentary discussion, relevant experiences in exploiting remotely sensed imagery to operatively support post fire management, with distinctive reference to burnt scar perimeter mapping and damage severity assessment, by case studies mainly from Italy.

\section{Burnt area mapping}

Detailed burnt area mapping (reference scales: 1:5000-1:25000) may be operatively based on: exclusive use of field data (GPS, laser station, etc.), exclusive use of remotely sensed data, data integration (remotely sensed + field data).

\section{Field-based survey}

Burnt scar perimeter mapping based on field work only (walking along the boundaries of the burnt area with a GPS device) is theoretically the best option, being a rather objective way to directly acquire the field truth. However, such an approach may have several shortcomings: possible technical problems from GPS, e.g., because of radio signal lacking due of satellite position; residual vegetation coverage; orography; rainfall; etc.; difficulties in identifying burnt scar perimeter in the case of patchy fires; low accessibility for a safe work of the field team; large extension of the burnt stands. 
When such shortcomings becoame operatively relevant, then the following options for the field work may be considered:

- field mapping based on digital orthophotos supported by a digital based topographic map (at least at 1:10000 scale) loaded on a palm or tablet PC connected with GPS: in a standard GIS environment the operator can digitise manually the boundary of the fire visually localized;

- proximal sensing: the method is based on the availability of a multiple station made by a GPS and a laser collimeter connected together by a palm or tablet PC; the operator, located on a favourable point of view, looks at the burnt area, registers its position by GPS and then acquires the coordinates of some relevant points of the burnt area with the laser instruments; such a procedure is particularly suitable in case of low accessibility on the burnt stand, when fire boundary is rather regular or even in the case of patchy fires (in latter case, a distant point of view can simplify the identification of the scar perimeter); however, the procedure requires specific equipment and technical skill and it has to be carried out just after the event, especially under Mediterranean conditions where vegetation regrowth is very fast.

\section{Remote sensing-based survey}

Burnt areas have a typical spectral signature, especially if analysed by a multitemporal approach, because of the different ground coverage between pre-fire (vegetation) and post-fire (white ash, black ash, bare soil, dead vegetation) conditions (Lentile et al 2006).

Aerial photography has an high efficiency potential for detecting and delineating burnt areas, especially in the case of light aerial vectors and in the case of sensors capturing infrared (IR) and near infrared (NIR) reflectances. However, in the last decade the most growing segment of remote sensing is that of passive (optical) multispectral imagery from satellites for earth observation (EO), due to the relative lowering of the costs and increasing spatial resolution (Wuldner \& Franklin 2003). Almost all the different types of available passive and active EO imagery have been tested for experimental tests and/or for developing operative services for fire risk forecasting, near real time alarm and support for fire fighters, burnt area mapping, quantification of burnt biomass, evaluation of fire severity and damage assessment, and vegetation regrowth monitoring.

As mentioned, for most post-fire operational applications, high (HR) and, above all, very high (VHR) resolution data are particularly suitable today: they are characterized by improved information depth (over 8 bit per pixel per spectral band), fairly high signal-to-noise ratios and allow mapping with a
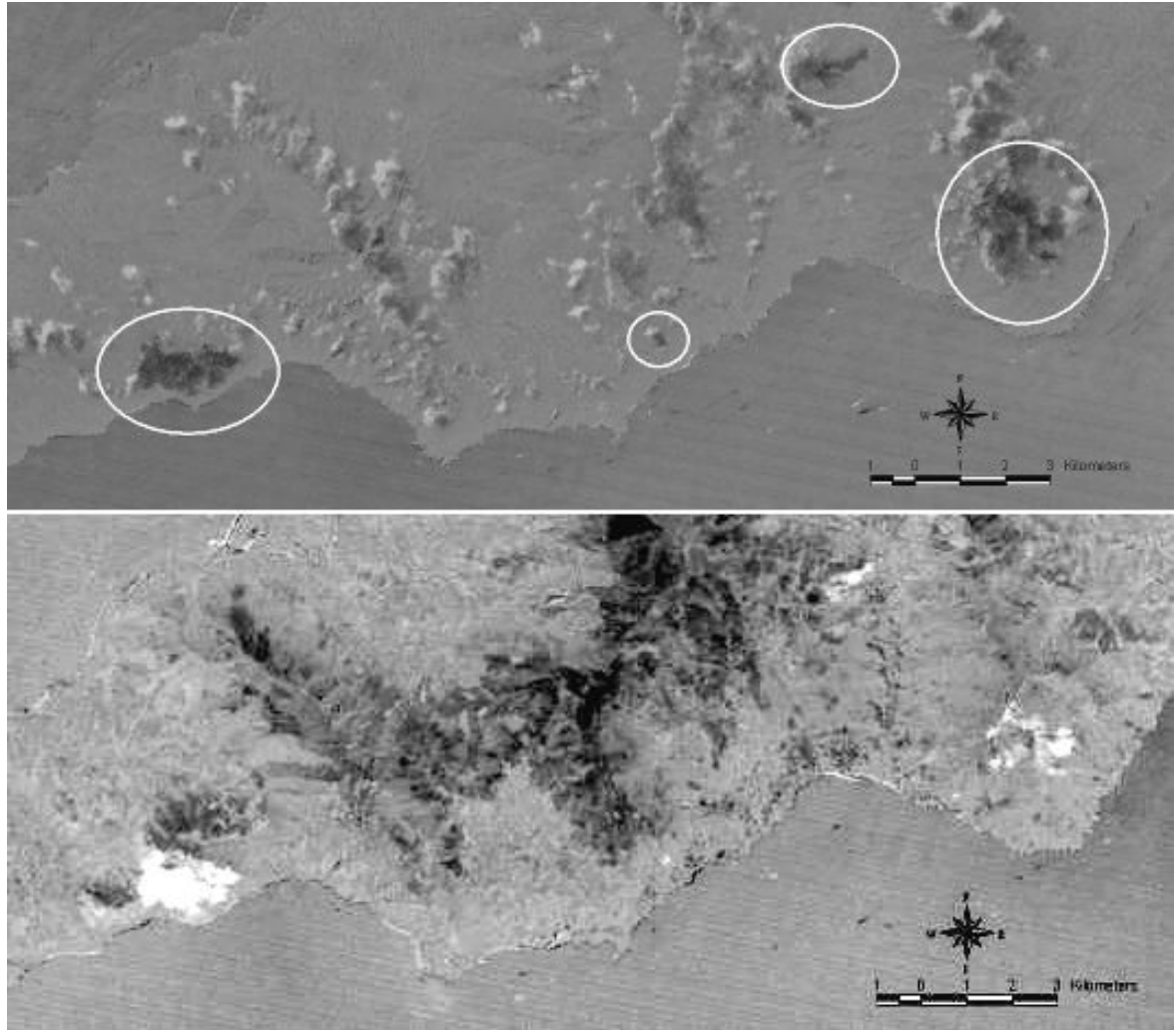

Fig. 1 - Example of the behaviour of MNI index to identify burnt forest stands in Campania (Central Italy) by the near infrared band from Landsat 7 ETM+ images. Above, MNI index elaborated from a post-fire image acquired the $2^{\text {nd }}$ of August 2000 and a pre-fire image acquired the $1^{\text {st }}$ of July 2000: the areas with lower photosynthetic activity are darker. Below, MNI index for the same area from a post-fire image acquired the $2^{\text {nd }}$ of August 2000 and an image acquired during the following growing season ( $1^{\text {st }}$ of May 2001): the areas with increasing photosynthetic activity are lighter. White circles in the above image identify the burnt areas.

consistent geometrical reliability for management purposes (e.g., panchromatic : $10 \mathrm{~m}$ for Spot HRV; $6 \mathrm{~m}$ for IRS-1C and Spot 4; $2.5 \mathrm{~m}$ for Spot $5 ; \leq 1 \mathrm{~m}$ for Quickbird and Ikonos; $\leq 0.5 \mathrm{~m}$ for the upcoming WorldView-1 and GeoEye-1).

Image classification methods may be based on manual photointerpretation or on automatic/semiautomatic image processing algorithms (Franklin 2001, Lillesand et al. 2004). The approach may be mono-temporal, based on the acquisition of just a single postfire image, or multi-temporal, based on the acquisition of at least two images, one prefire and one post-fire.

Monotemporal approach is relatively cheap and of easy technical implementation. However, the identification of burnt areas may be difficult if the image is acquired during the spring or it is temporally distant from the event. In such situations, the vegetation regrowth may change the spectral signature of the burnt area which may become similar to that of the surrounding unburnt land cover. Classification problems may also arise when forest and non-forest fires have to be distinguished. The monotemporal approach is commonly applied by HR/VHR data. Distinctively, object oriented-based techniques can significantly improve the detection of burnt area mapping by VHR data (Gitas et al. 2004, Mitri \& Gitas 2004, 2006). In the case of medium-low resolution data (pixels of size between 180-250 $\mathrm{m}$ and $1 \mathrm{~km}$ ), burnt areas pixels frequently have a mix signature with averaged digital numbers corresponding also to unburnt ground coverages.

In the case of multitemporal approach, based on the acquisition of (at least) two images (pre- and post-fire), the identification of burnt area is as easier as the post-fire image is acquired temporally closer to the event. The classification of the area based on the type of vegetation burnt is more feasible than the monotemporal approach. However, the multitemporal method is more expensive and technically complex to be implemented, since all the images have to be geometrically co-registered and spectrally normalised.

Multitemporal low and medium resolution EO data are frequently used for monitoring big forest fires over large territories (e.g. Stroppiana et al. 2003, Csiszar et al. 2005). $\mathrm{HR} /$ VHR imagery is usually exploited to 
support post-fire management by: (i) comparison of the digital numbers from selected bands or their combination (vegetation indices), before and after the fire; (ii) comparison of the classifications independently carried out before and after the fire.

Beyond the well known NDVI (Normalized Difference Vegetation Index) and IRI (Infrared Index), which exploit the reflectances in the red and NIR bands, the most effective vegetation indices for forest burnt area mapping prove to be NBR (Normalized Burned Ratio), based on red and SWIR bands, and NBRT, a modification of the latter which includes also the so called "scaled brightness temperature" derived from the thermic band (Holden et al. 2005).

The multitemporal quantitative comparison can be normalised through the MNI index, ranging between -1 and $+1, M N I=$ image $_{\text {post }}$ - image $\left._{\text {pre }}\right) /\left(\right.$ image $_{\text {post }}+$ image $\left._{\text {pre }}\right)$, where image is a vegetation index or the digital number of a given band, image post is acquired after the fire event and image $e_{\text {pre }}$ is acquired before the fire event. MNI index may be applied in order to identify burnt areas also on the basis of post-fire regrowth: acquiring im$a g e_{\text {pre }}$ just after the fire and image $e_{\text {post }}$ some time after, in the resulting MNI image the burnt areas are usually characterized by sig nificantly higher values than the surroundings (Chirici \& Corona 2005).

\section{Operative case studies}

\section{Cadastral geodatabases of burnt areas in Campania (Southern Italy)}

Regione Campania has implemented a cadastral geodatabase of burnt areas for the years from 2000 to 2003 in order to answer legal specifications settled by the already mentioned Italian regulation on forest fires (Law no. 353/2000).

The mapping procedure was based on a two-step approach. In a first phase, for each year an unsupervised analysis of multitemporal Landsat 7 ETM+ imagery was carried out in order to identify those areas with a spectral behaviour compatible with a forest fire event. For such a task, the MNI index based on band 4 (NIR channel) of Landsat 7 $\mathrm{ETM}+$ sensor was determined as the best tool for an unsupervised approach, confirming previous experiences (Bottai et al. 2000). In the MNI image, burnt areas have lower values than unburnt ones because of decreased level of photosynthetic activity (Fig. 1). However, such a spectral behaviour is compatible also with other events such as forest clearcuttings that, on the other hand, may be distinguished because of their regular geometric shapes. For each year of analysis several MNI images were elaborated in order to automatically identify burnt areas also on the basis of post fire photosynthetic decrease and regrowth photosynthetic in- crease. The final result is a reliable database of possible burnt areas.

In the second step, each possible burnt area were assessed also combining the geodatabase of field surveys acquired by the National Forest Service. If a possible fire was confirmed by official field report, the perimeter of burnt area was digitised manually at a reference scale of 1:10000 on the basis of digital orthophotos, yearly acquired, and digital topographic maps. The resulting final geodatabase of burnt areas was finally overlayed with digital cadastral maps in order to identify landowners for the application of the National Law no. 353/2000. A total number of 19 Landsat images was elaborated in order to identify 2080 forest fires, for a total burnt area, in four years, of 23068 ha (Grasso et al. 2004).

\section{European Forest Fire Rapid Damage As- sessment System}

At the European level, the EFFIS service (see Introduction) analyses a multitemporal database of medium resolution EO images to map forest fires larger than 50 ha for each Mediterranean country (Portugal, Spain, France, Italy, Greece), every year. All the information is stored in a module referred to as EFFIS Rapid Damage Assessment (RDA) and it performes the evaluation of damages at least twice during a fire campaign. The service is implemented by the Joint Research Centre of the European Commission of Ispra (EC-JRC) since 1997 supporting the Forest Focus regulation (EC-2152/2003) (EC 2006).

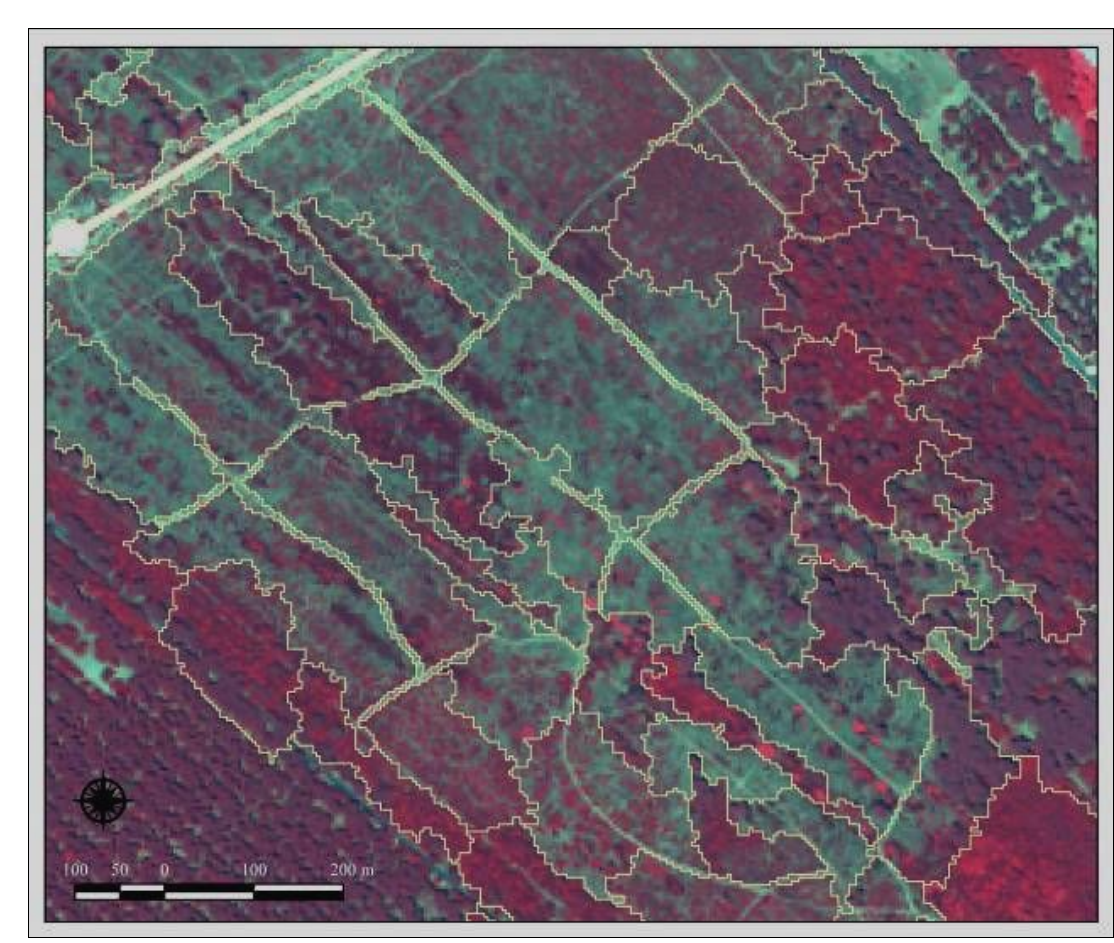

Fig. 2 - Multiresolution segmentation of an Ikonos image of burnt forest stands after six years from the event (Castel Fusano, Rome, Italy).
The RDA procedure is based on the multitemporal analysis of MODIS images acquired during the vegetation season in order to identify the events. In a second step, burnt areas boundaries are overlaid with Corine Land Cover vector database to identify burnt land covers. For each country quantitative relationships have been established between fire statistics from national authorities and large forest fires mapped by RDA module. Hence, the EFFIS RDA system is able to estimate yearly the total forest burnt area on a national level for the considered countries, with good accuracy (EC 2006). However, the produced figures have only a statistical meaning, and even for large fires they cannot be used for burnt area monitoring at the detailed scale required by post fire management (legal framework, reclamation and restoration activities, etc.).

\section{Object-based approach}

Object-based techniques are particularly efficient to exploit the information by HR/VHR remotely sensed data (Benz et al. 2004). They have been successfully used to accurately map burnt forest stands in many Mediterranean areas. Mitri \& Gitas (2006) developed an object-oriented model using a post-fire Ikonos imagery of Thasos island (Greece) to distinguish between surface and canopy burn by a monotemporal approach: the overall accuracy of classification was 0.87. A similar level of classification accuracy is reported by Chirici \& Corona (2006) with reference to events occurred in northern Latium (central Italy) assessed by MNI in- 
dex applied to multitemporal QuickBird images. Chirici et al. (2006) also report the remote sensing assessment of post-fire forest recovery after a large wildfire occurred in the Cilento National Park (Southern Italy); the recovery dynamics was monitored by various approaches applied to multitemporal Landsat images from 1993 to 2004: the most accurate results were obtained by multiresolution segmentation and object-oriented classification, compared to pixel-based approaches. De Matteo et al. (2007) reported the possible operative use of segmentation techniques applied to QuickBird post-fire imagery in Alpine areas, with errors ranging from 3 to $20 \%$ in respect to field assessment.

Fig. 2 shows an example of multiresolution segmentation of an Ikonos image of a Mediterranean forest stand six years after the fire. The obtained segments (polygons) delineating different patches of recovering vegetation are of direct support for stratification of restoration planning (no intervention, seeding, planting, etc.).

\section{Damage assessment}

Multispectral remotely sensed images are of great potential for classifying and mapping the severity of fire damages to forest vegetation. The overall view of the burnt areas and the possibility of analyzing multispectral reflectance make such imagery able to detect and qualify damages even better than visual assessment by field teams (Franklin 2001, Wang et al. 2004).

\section{Aerial assessment: the SIMiB project}

The SIMiB project (System for Mapping Forest Fires), funded by the Italian National Forest Service, has tested the Duncan

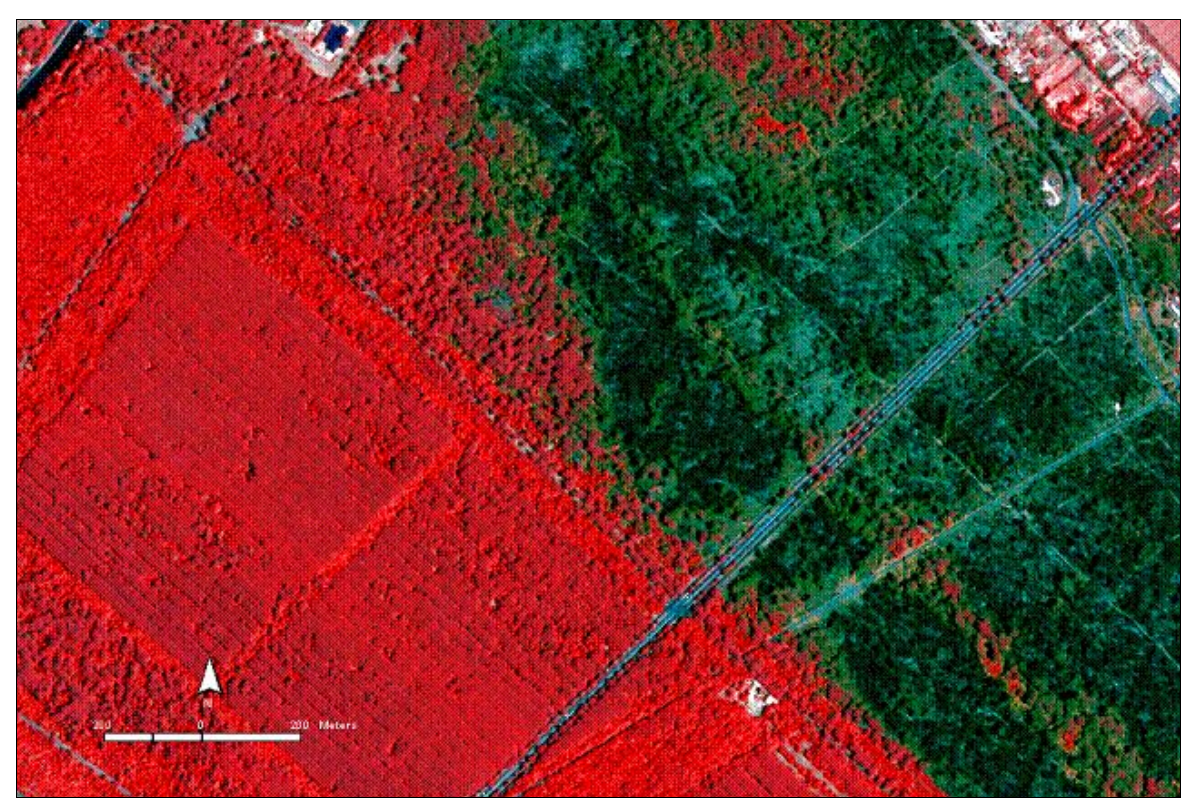

Fig. 4 - Pansharpened near-infrared Ikonos image acquired after the forest fire in the woodland of Castelfusano (Rome, Italy). Burnt areas are in green and black. Unburnt areas are represented by the red canopies, characterized by high photosynthetic activity.

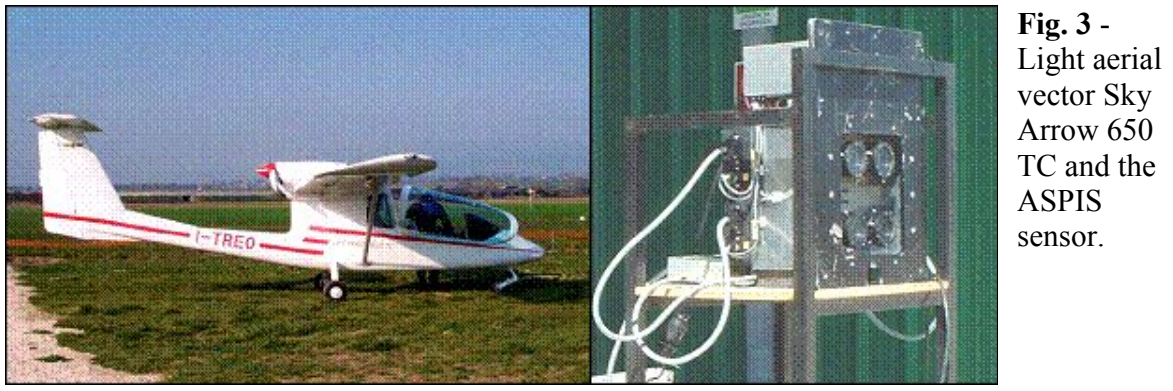

MS4100 (Duncan-Flir-Riegl) sensor, a multispectral tool carried by an aerial light vector (SKY-ARROW 650TC). The sensor is based on three CCD cameras active in the visible and near-infrared bands and one active in the thermal infrared band. Infrared false colour digital images are produced and orthocorrected with a nominal accuracy of \pm $1 \mathrm{~m}$ in order to identify burnt area boundary, to map damage levels and to estimates emissions of $\mathrm{CO}_{2}$ caused by forest fire and hypotethical recoils on Kyoto Protocol (Carlini et al. 2006). An example of a similar device suitably carried by light aerial vector for post-fire assessment is the ASPIS sensor (Fig. 3) developed by the University of Tuscia (Italy). The methodology has proven to provide successfully monitoring results over $2000 \mathrm{~km}^{2}$ in Central Italy (Lazio) allowing to map forest burnt areas with an accuracy compatible with 1:10000 scale level. Remote sensing by aerial light vectors can be efficiently (in terms of imagery quality and cost) used to map and qualify with high accuracy damages on distinctive spots, and it is also particularly suitable for calibrating remotely sensed imagery of lower geometric resolution (Oertel et al. 2003). bands 4, 3 and 2 (Fig. 4). The image had the resolution of the panchromatic channel (1 $\mathrm{m}$ ), and it could be effectively overlaid to forest road and timber yarding network for supporting harvesting planning to remove burnt and partially unburnt material and to secure the area (Chirici et al. 2001).

\section{Field assessment and attribute spazial- ization}

The restoration of forest and other wooded land damaged by wildfires should be designed through the analysis of vegetation syndynamics and dendrostructural features of the residual stands.

For such tasks, the implementation of a network of field permanent geocoded sample plots is required to follow post-fire natural dynamics and regrowth effectiveness. The use of several small sample plots, of size around $10-20 \mathrm{~m}^{2}$ in burnt forest stands, is usually better than a few large plots, at least considering the monitoring just after the fire (Corona et al. 1998). Attributes to be measured are, for instance: deadwood; tree natural regeneration (sexual and vegetative); vegeta- 
Fig. 5 - Broadleaves natural regeneration index (gamic regeneration) spatialised on the basis of a multiregression analysis by QuickBird post-fire image and field data in the Castelfusano woodland (Rome, Italy).

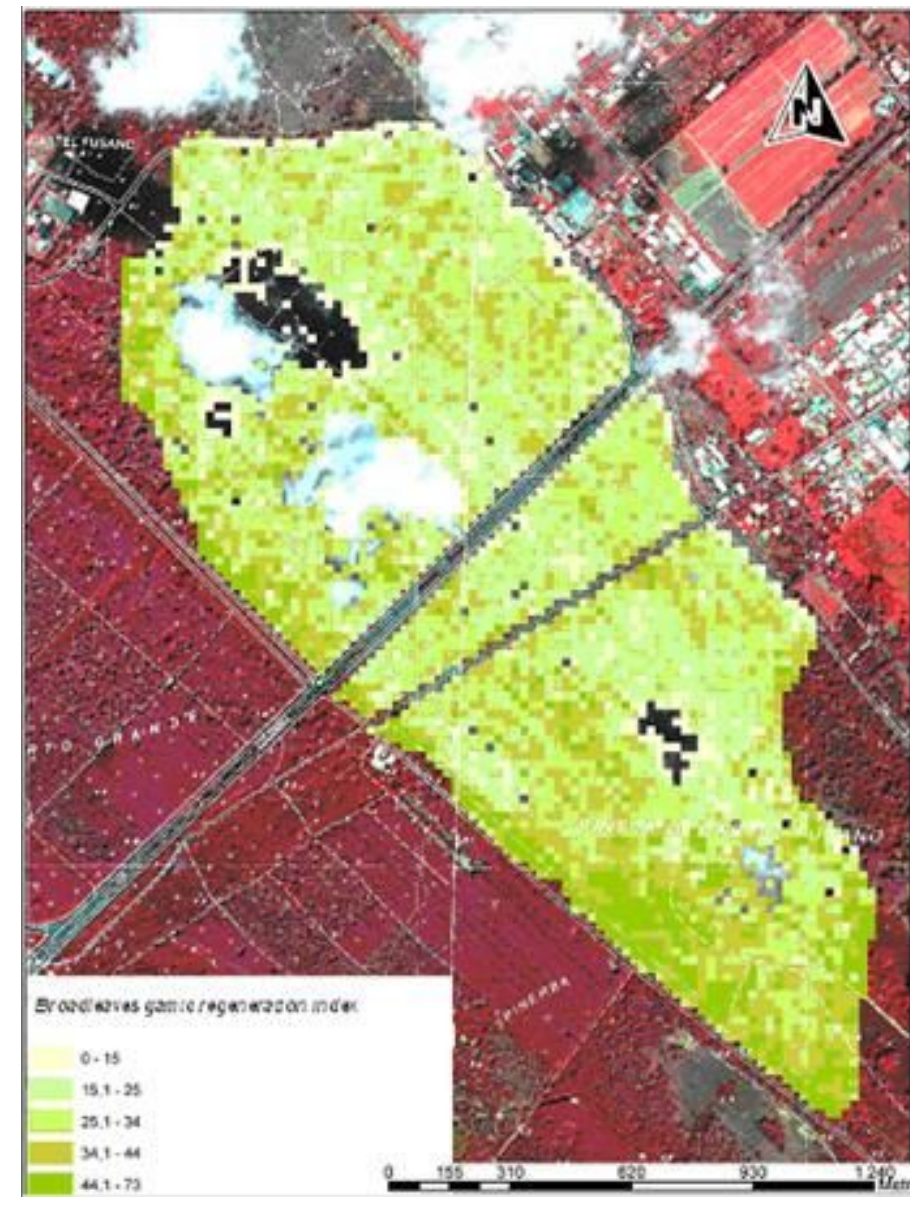

tion diversity.

Field inventoried data may be spatialized in order to produce map of the main interesting attributes, using parametric or non-parametric statistical tools, and, preferably, integrating independent information from remotely sensed images (e.g., through multiregression or $k$-Nearest Neighbour procedures).

An example of the application of a parametric correlation method to describe the post-fire broadleaves tree regeneration in the Castelfusano forest is presented in Fig. 5. Post-fire natural regeneration mapping was carried out integrating GPS geocoded field data collected in 178 rectangular transects of $20 \mathrm{~m}^{2}$ each with spectral data from a QuickBird image. Information acquired in the field were related to spectral data of the QuickBird image and to soil types in order to establish a statistical relationships for spatializing a tree regeneration index. A multiple linear stepwise regression procedure was succesfully applied: band 4 and SAVI (Soil Adjusted Vegetation Index) from QuickBird imagery resulted as the most significant predictors of the broadleaf sexual regeneration in the considered area.

\section{Selected ongoing applied developments}

Research in the field of remote sensing technology applied to support forest fire fighting (risk prediction, early detection) and monitoring has been rather active in the last decades. Most of the efforts are focused on large fires, as those carried out at EC-JRC leading to the mentioned EFFIS RDA service. However, it is deemed interesting to give here some selected hints on other ongoing applied research programs: more detailed information can be found on many Internet websites.

European Space Agency (ESA) developed a multi-year global fire atlas (ATSR World Fire Atlas) starting in the 1995 and based on data acquired by the Along Track Scanning Radiometer (ATSR) sensor on ERS-2 satellite, launched in 1995, and the Advanced Along Track Scanning Radiometer (AATSR) sensor on Envisat satellite, launched in 2002. Burning fires are classified measuring thermal infrared radiation at night by ATSR/AATSR sensors. These data are available to registered users online in near-real time (ESA asserts approximately six hours after the acquisition - Fig. 6)

As part of the GMES Service Elements Initiative of ESA, the Risk-Eos team defines, develops and delivers a set of experimental services for flood and fire risks management, utilizing the capabilities of satellite observation in combination with other data sources and models: the target is to map burnt areas and monitoring of vegetation evolution with decametric resolution (minimum mapping unit $=1 \mathrm{ha}$ ). This service is currently delivered over various regions of Spain, France and Italy, in particular burn scar mapping is delivered in Basilicata, Sicilia and Sardegna region covering an area of $60000 \mathrm{~km}^{2}$. Complement to burn scars mapping is the rapid mapping products for large fires to support the International Charter for major events and local collectivities.

Potentially relevant activities are those by the COSMO-SkyMed project developed un-

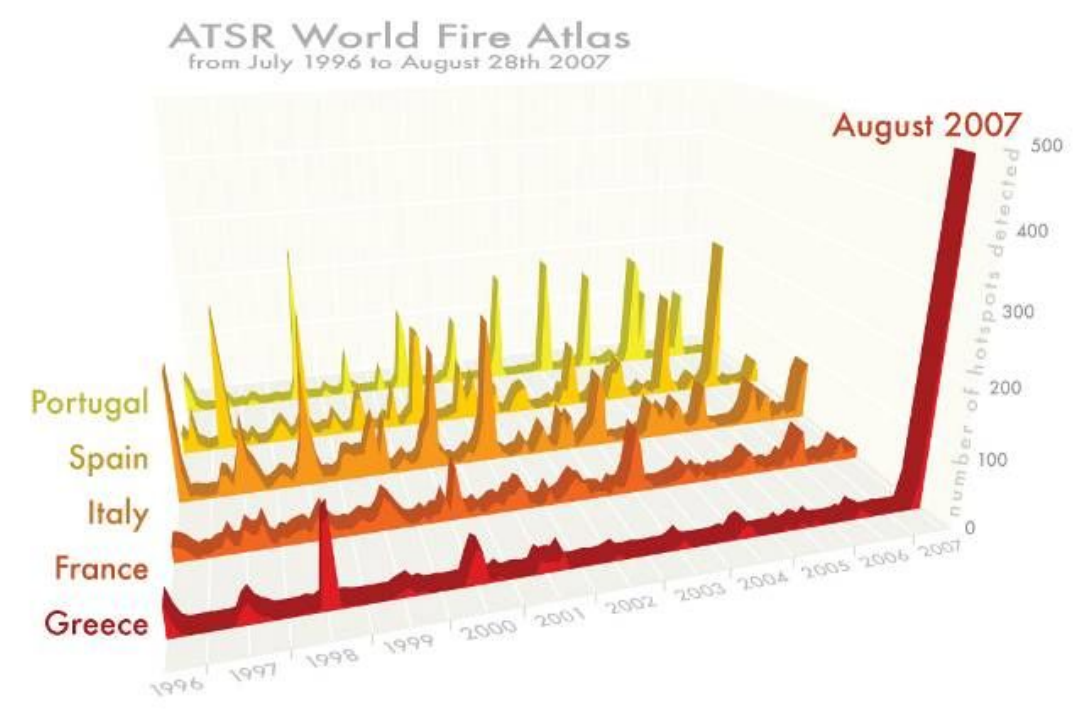

Fig. 6 - ATSR World Fire Atlas. Number of fires occurring monthly for France, Italy, Spain, Portugal and Greece from July 1996 to August 2007. Source: European Space Agency, 2007. [online: september 2007] URL: http:/www.esa.int/images/stats_H.jpg. 
der the responsibility of the Italian Space Agency. The service is based on a minisatellite constellation (4 medium-size satellites), equipped with a microwave high resolution synthetic aperture radar (SAR) operating in $\mathrm{X}$-band, designed to pick up data of environmental interest with frequent revisiting time The system will be devoted to the civil protection, environmental and climate monitoring, prevention of the catastrophes, control of the coasts, soil conservation, etc., mainly for the area of the Mediterranean (prevention, alarm, crisis management, post-crisis tools). The first two satellites were successfully launched on June 2007, while the launch of the other two satellites will be completed within the early 2009.

In the United States, fire fighting strategy is based on the idea of concentrating all the possible efforts to implement a unique coordinated service. The Geological Service coordinates the development of the Wildland Fire Support, an information service devoted to collect all data useful for prevention, alarm and monitoring of wild fires. The service is available on-line (http://www.geomac.gov) both for the citizens interested in having information of forest fires and for fire fighters who may also upload data from field monitoring. Near-real time monitoring programme, based on Modis and Noaa-Avhrr data, acquires daily images to identify hot spots and to monitor large events. Mapping activities are prevalently oriented to large fire monitoring because fire events in the USA cover frequently very large wild areas of difficult accessibility.

\section{Conclusion}

The last International Wildland Fire Conference held in Sevilla (Spain, May 2007) has once more stressed the importance of proper strategies for post fire management based on sound monitoring, not only to pinpoint the actual consequences of wildfires on land cover, land use and the environment (climate included) but also to support effective interventions fostering ecological and economical restoration of the struck territorial systems.

This note has highlighted the potential of consistent remote sensing tools for surveying and monitoring burnt forest areas. However, applied research is still required, distinctively to develop and refine procedures for monitoring small fires (smaller than $10 \mathrm{ha}$ ) over large territories, like those typical of most European countries (Mediterranean ones included). Moreover, the assessment of forest burnt area is not enough: the development of reliable tools for the quantitative assessment of forest damages, biomass loss and carbon emissions due to wildfires is to be significantly advanced.

Futhermore, from a practical side, future research efforts needs to be oriented towards an effective integration of available data sources. For instance, for the implementation of a national system for mapping forest burnt stands at 1:10000 scale in a country like Italy or Spain, the most effective current scenario might be the modular integration of GPS field surveys with targeted acquisitions (with respect to areas difficult to be field-surveyed because of low accessibility or GPS signal lacking or in the case of very wide and/or very patchy fires) of multispectral imagery by aerial light vectors or satellites carrying VHR sensors, even eventually coupled with targeted acquisitions (one at the beginning and one at the end of the fire season) by medium resolution satellite imagery on larger scales.

\section{Acknowledgements}

The work, carried out by the Autors in equal parts, has been partially funded by the Italian Ministry for Research and University under the project CarboItaly (FISR funds). The Authors thanks Agriconsulting S.p.A. for allowing the use of data presented in the paragraph "Cadastral geodatabases of burnt areas in Campania".

\section{References}

Benz UC, Hofmann P, Willhauck G, Lingenfelder I, Heynen M (2004). Multi-resolution, object-oriented fuzzy analysis of remote sensing data for GIS-ready information. ISPRS Journal of Photogrammetry \& Remote Sensing 58: 239-258.

Bottai L, Bagnoli M, Oradini A, Carnemolla S (2000). Satellite based monitoring of Tuscany wildfires. In: Remote sensing and forest monitoring (Zawila-Niedzwiecki T, Brach $\mathrm{M}$ eds), Office for Official Pubblications of the European Communities. European Commission, Luxembourg, Environment and quality of life series XII: 573-583

Carlini M, Valentini R, Belli C, Capitoni B, Papale D (2006). Progetto SIMIB: mappe degli incendi e valutazione dei danni da oggi a portata di mouse. Silvae 5: 73-98.

Chirici G, Corona P, Dellisanti R, Di Giovine M, Marchetti M, Rossini P, Travaglini D (2001). Confronto e integrazione di dati telerilevati Ikonos e Landsat 7 ETM+ nella valutazione dei danni da incendio in ambiente mediterraneo: il caso della pineta di Castel Fusano. In: Atti, Conferenza ASITA, La qualità nell'informazione geografica, Rimini, volume I, pp. 529-537.

Chirici G, Corona P (2005). An overview of passive remote sensing for post-fire monitoring. Forest@ 2 (3): 282-289. [online] URL: http://www.sisef.it/forest@

Chirici G, Corona P (2006). Utilizzo di immagini satellitari ad alta risoluzone nel rilevamento delle risorse forestali. Aracne Editrice, Roma, Italy.

Chirici G, Marchetti M, Mattioli W, Ottaviano M, Lamonaca A, Corona P (2006). Confronto di approcci correlativi per il monitoraggio satellitare del recupero post-incendio della vegetazione forestale. Atti della $10^{\circ}$ Conferenza Nazionale
ASITA, Bolzano, 14-17 novembre 2006, pp. 685-690.

Corona P, Saracino A, Leone V (1998). Plot size and shape for the early assessment of post-fire regeneration in Aleppo pine stands. New Forests 16: 213-220.

Csiszar I, Denis L, Giglio L, Justice CO, Hewson J (2005). Global fire activity from two years of MODIS data. International Journal of Wildland Fire 14: 117-130.

Davis MA, Curran C, Tietmeyer A, Miller A (2005). Dynamic tree aggregation patterns in a species-poor temperate woodland disturbed by fire. Journal of Vegetation Science 16: 167-174. De Matteo E, Colombo R, Meroni M, Comini B, Fracassi G, Cavini L, Olivieri M, Deligios G (2007). Delimitazione di aree boschive montane percorse dal fuoco mediante immagini satellitari ad alta risoluzione geometrica. Forest@ 4 (3): 264-271. [online] URL: http://www.sisef.it/forest@/

Diaz-Delgado R, Lloret F, Pons X (2003). Influence of fire severity on plant regeneration by means of remote sensing imagery. International Journal of Remote Sensing 24: 1751-1763.

EC (2006). Forest Fires in Europe 2005. European Commission, Joint Research Centre, Institute for Environment and Sustainability, Report No 6, EUR 22312 EN, Italy.

Eva H, Lambin EF (1998). Burnt area mapping in Central Africa using ATSR data. International Journal of Remote Sensing 19: 3473-3497.

Franklin SE (2001). Remote sensing for sustainable forest management. CRC Press, Boca Raton, USA.

Gitas I, Mitri G, Ventura G (2004). Object-oriented image analysis for burned area mapping using NOAA-AVHRR imagery in Creus Cape, Spain. Remote Sensing of Environment 92: 409413.

Grasso E, Molinari P, Mandatori R (2004). Il catasto degli incendi boschivi della Regione Campania: un sistema su WEB per l'applicazione della Legge Quadro 353/2000. MondoGIS 44: 31-34.

Henry MC, Hope AS (1998). Monitoring postburn recovery of chaparral vegetation in southern California using multi-temporal satellite data. International Journal of Remote Sensing 19: 3097 3107.

Holden ZA, Smith AMS, Morgan P, Rollins MG, Gessler PE (2005). Evaluation of novel thermally enhanced spectral indices for mapping fire perimeters and comparisons with fire atlas data. International Journal of Remote Sensing 26: 48014808.

Lentile LB, Holden ZA, Smith AMS, Falkowski MJ, Hudak AT, Morgan P, Lewis SA, Gessler PE, Benson NC (2006). Remote sensing techniques to assess active fire characteristics and post-fire effects. International Journal of Wildland Fire 15: 319-345.

Lillesand TM, Kiefer RW, Chipman JW (2004). Remote Sensing and Image Interpretation. Fifth Edition. John Wiley \& Sons, USA.

McHugh C, Kolb TE (2003). Ponderosa pine mor- 
tality following fire in northern Arizona. International Journal of Wildland Fire 12: 7-22.

Mitri GH, Gitas IZ (2004). A semi-automated object-oriented model for burned area mapping in the Mediterranean region using Landsat-TM imagery. International Journal of Wildland Fire 13 367-376

Mitri GH, Gitas IZ (2006). Fire type mapping using object-based classification of Ikonos imagery. International Journal of Wildland Fire 15: 457-462.

Moya D, Espelta JM, Verkaik I, Lopez-Serrano F, de las Heras J (2007). Tree density and site quality influence on Pinus halepensis Mill. reproductive characteristics after large fires. Annals of Forest Science 64: 649-656.

Oertel D, Briess K, Halle W, Neidhardt M, Lorenz
E, Sandau R, Schrandt F, Skrbek W, Venus H, Walter I, Zender B, Zhukov B, Goldhammer JG, Held AC, Hille M, Brueggemann H (2003). Airborne forest fire mapping with an adaptive infrared sensor. International Journal of Remote Sensing 24 (18): 3663-3682.

Raftoyannis Y, Spanos I (2005). Evaluation of log and branch barriers as post-fire rehabilitation treatments in a Mediterranean pine forest in Greece. International Journal of Wildland Fire 14: 183-188.

Smith AMS, Wooster MJ, Powell AK, Usher D (2002). Texture-based feature extraction: application to burn scar detection in Earth Observation satellite imagery. International Journal of Remote Sensing 23: 1733-1739.

Stroppiana D, Gregoire J-M, Pereira JMC (2003).
The use of SPOT VEGETATION data in a classification tree approach for burnt area mapping in Australian savana. International Journal of Remote Sensing 24 (10): 2131-2151.

Turner MG, Romme WH, Gardner RH, Hargrove WW (1997). Effects of fire size and pattern on early succession in Yellowstone National Park. Ecological Monographs 67: 411-433.

Wang J, Rich PM, Price KP, Kettle WD (2004). Relations between NDVI and tree productivity in the central Great Plains. International Journal of Remote Sensing 25 (16): 3127-3138.

Wulder MA, Franklin SE (2003). Remote Sensing of Forest Environments: Concepts and Case Studies. Kluwer, Dordrecht, Netherlands. 